\title{
Microbial population dynamics in urban organic waste anaerobic co-digestion with mixed sludge during a change in feedstock composition and different hydraulic retention times
}

Fitamo, Temesgen Mathewos; Treu, Laura; Boldrin, Alessio; Sartori, Cristina; Angelidaki, Irini; Scheutz, Charlotte

Published in:

Water Research

Link to article, DOI:

10.1016/j.watres.2017.04.012

Publication date:

2017

Document Version

Peer reviewed version

Link back to DTU Orbit

Citation (APA):

Fitamo, T. M., Treu, L., Boldrin, A., Sartori, C., Angelidaki, I., \& Scheutz, C. (2017). Microbial population dynamics in urban organic waste anaerobic co-digestion with mixed sludge during a change in feedstock composition and different hydraulic retention times. Water Research, 118, 261-271.

https://doi.org/10.1016/j.watres.2017.04.012

\section{General rights}

Copyright and moral rights for the publications made accessible in the public portal are retained by the authors and/or other copyright owners and it is a condition of accessing publications that users recognise and abide by the legal requirements associated with these rights.

- Users may download and print one copy of any publication from the public portal for the purpose of private study or research.

- You may not further distribute the material or use it for any profit-making activity or commercial gain

- You may freely distribute the URL identifying the publication in the public portal 


\section{Accepted Manuscript}

Microbial population dynamics in urban organic waste anaerobic co-digestion with mixed sludge during a change in feedstock composition and different hydraulic retention times

Temesgen Fitamo, Laura Treu, Alessio Boldrin, Cristina Sartori, Irini Angelidaki, Charlotte Scheutz

PII: S0043-1354(17)30267-1

DOI: 10.1016/j.watres.2017.04.012

Reference: WR 12809

To appear in: Water Research

Received Date: 9 January 2017

Revised Date: 22 March 2017

Accepted Date: 4 April 2017

Please cite this article as: Fitamo, T., Treu, L., Boldrin, A., Sartori, C., Angelidaki, I., Scheutz, C., Microbial population dynamics in urban organic waste anaerobic co-digestion with mixed sludge during a change in feedstock composition and different hydraulic retention times, Water Research (2017), doi: 10.1016/j.watres.2017.04.012.

This is a PDF file of an unedited manuscript that has been accepted for publication. As a service to our customers we are providing this early version of the manuscript. The manuscript will undergo copyediting, typesetting, and review of the resulting proof before it is published in its final form. Please note that during the production process errors may be discovered which could affect the content, and all legal disclaimers that apply to the journal pertain. 


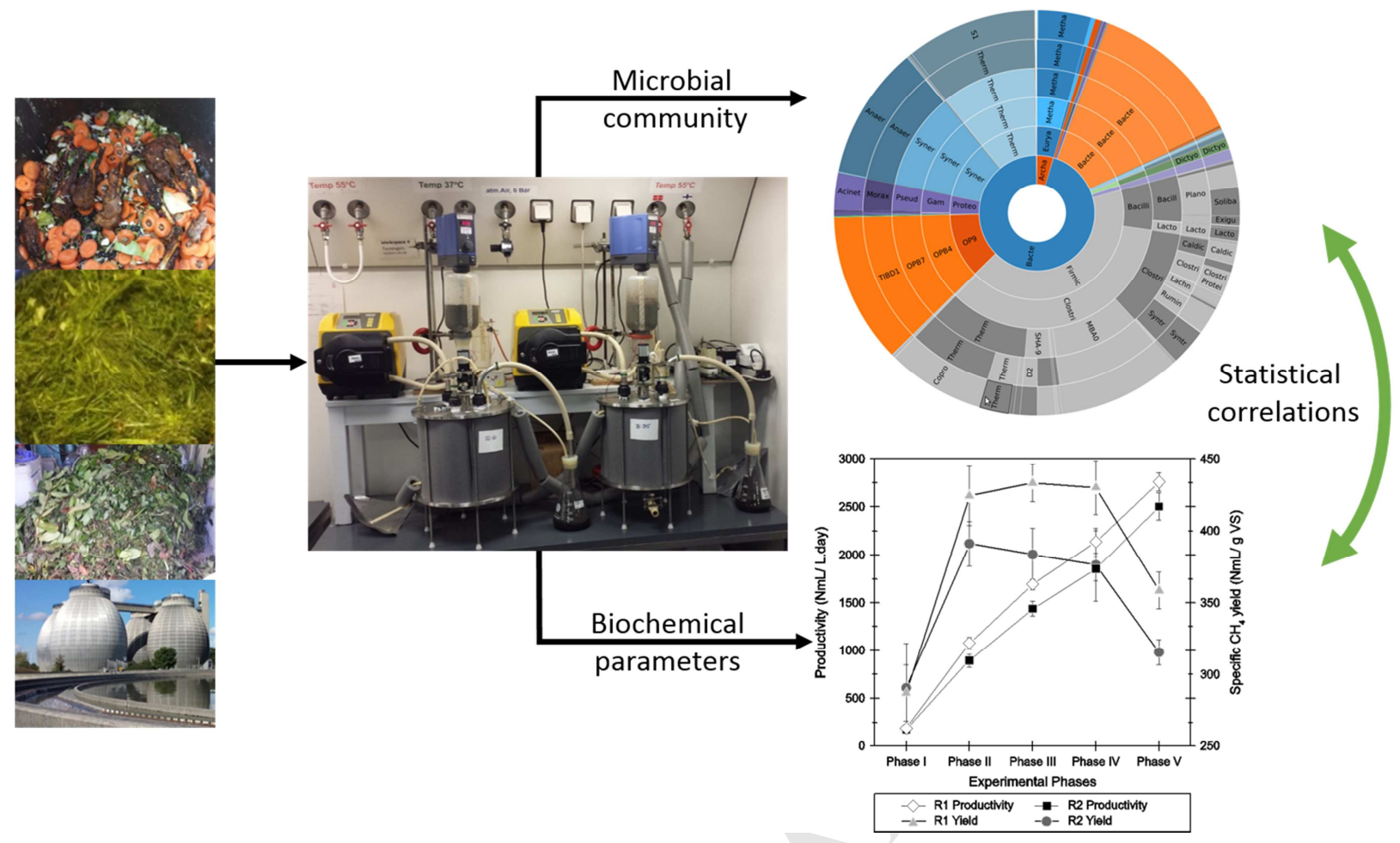


1

2

3

4

For submission to Water Research (2017-0-09)

Revised Manuscript

Microbial population dynamics in urban organic waste anaerobic co-digestion with mixed sludge during a change in feedstock composition and different hydraulic retention times

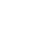

Temesgen Fitamo $^{1 *}$, Laura Treu ${ }^{1,2}$, Alessio Boldrin ${ }^{1}$, Cristina Sartori $^{2}$, Irini Angelidaki ${ }^{1}$, Charlotte Scheutz ${ }^{1}$

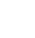

${ }^{1}$ Department of Environmental Engineering, Technical University of Denmark, Miljoevej, Building 115, DK-2800 Kgs. Lyngby, Denmark 2

3

\footnotetext{
${ }^{2}$ Department of Agronomy, Food, Natural resources, Animal and Environment (DAFNAE), viale dell’Università, 16, 35020 Legnaro (Padova), Italy.
}

5

\section{${ }^{*}$ Corresponding author}

Department of Environmental Engineering, Technical University of Denmark, Bygningstorvet, Building 115

DK-2800 Kongens Lyngby, Denmark

Phone: (+45) 4525 1413,

Fax: (+45) 4593 2850,

E-mail: tefi@env.dtu.dk 

4 5 46 7 8

\section{Abstract}

Microbial communities play an essential role in the biochemical pathways of anaerobic digestion processes. The correlations between microorganisms' relative abundance and anaerobic digestion process parameters were investigated, by considering the effect of different feedstock compositions and hydraulic retention times (HRTs). Shifts in microbial diversity and changes in microbial community richness were observed by changing feedstock composition from monodigestion of mixed sludge to co-digestion of food waste, grass clippings and garden waste with mixed sludge at hydraulic retention times (HRT) of 30, 20, 15 and 10 days. Syntrophic acetate oxidation along with hydrogenotrophic methanogenesis, mediated by Methanothermobacter, was found to be the most prevalent methane formation pathway, with the only exception of 10 days' HRT, in which Methanosarcina was the most dominant archaea. Significantly, the degradation of complex organic polymers was found to be the most active process, performed by members of $S 1$ (Thermotogales), Thermonema and Lactobacillus in a reactor fed with a high share of food waste. Conversely, Thermacetogenium, Anaerobaculum, Ruminococcaceae, Porphyromonadaceae and the lignocellulosic-degrading Clostridium were the significantly more abundant bacteria in the reactor fed with an increased share of lignocellulosic biomass in the form of grass clippings and garden waste. Finally, microbes belonging to Coprothermobacter, Syntrophomonas and Clostridium were correlated significantly with the specific methane yield obtained in both reactors.

Keywords: anaerobic digestion, methanogenesis, 16S rRNA, microbial diversity, urban organic waste 


\section{Introduction}

The use of anaerobic digestion (AD) to treat wastewater and municipal organic waste has increased worldwide. AD is a complex biological process that converts biomass into biogas through different microbial pathways and biochemical reactions (Angelidaki et al., 1999; Appels et al., 2008; Favaro et al., 2013). One of its benefits is the recovery of biomethane, a versatile carrier of renewable energy, which can be used for electricity and heat production or as a transport fuel (Pöschl et al., 2010; Weiland, 2010). Mono-digestion of diluted substrates such as sewage sludge and manure is nowadays economically challenging because of the low energy production. Compared to mono-digestion, co-digestion of multiple substrates provides significant advantages, including a more balanced supply of nutrients, a diluting effect for toxic and inhibiting compounds and overall increased biogas production, the result of the enhanced supply of organic compounds (Mata-Alvarez et al., 2014, 2000).

Disturbances in the stability of the AD process can occur when operational parameters deviate from normal operating conditions, causing, for example, the accumulation of volatile fatty acids (VFAs) and ammonia, and a subsequent inhibition of microbial activity (Chen et al., 2008; Gerardi, 2003; Mao et al., 2015). Microbial diversity, activities and interactions can also be affected by process parameters (e.g. temperature and ammonia), which in turn affect overall AD performance (Goux et al., 2016; Lin et al., 2016). Understanding the microbial community structure and pathways in $\mathrm{AD}$ is thus important, to ensure the regular operation and performance of the $\mathrm{AD}$ process. Currently, due to technological advancements, general knowledge on AD microbial community compositions and the roles of bacteria and archaea in the degradation process is well established (Campanaro et al., 2016a; Eikmeyer et al., 2013). However, only a few studies have investigated correlations between microbial community composition and process parameters (Campanaro et al., 2016b; Luo et al., 2015; Rivière et al., 2009a). 
Biochemical pathways involved in the $\mathrm{AD}$ process are based on rather complex and diverse microbial roles. Therefore, it is important to understand the effect of the microbial community's composition and function with regard to the operational parameters required to operate the digester at optimum conditions and maximise energy recovery. Investigations conducted on seven anaerobic digesters fed with sewage sludge have revealed that the core group of bacteria common to all digesters is composed of six operational taxonomical units (OTUs) related to Chloroflexi, Betaproteobacteria, Bacteroidetes and Synergistetes (Rivière et al., 2009a). Sludge-based AD digesters - besides strict anaerobes - contain aerobic bacteria originating from the feedstock sludge, which basically consists of aerobic bacteria, and so Chloroflexi appear mainly in sludge-based AD processes. Another study regarding sewage sludge digesters has found that the most common archaeal taxa are Methanomicrobia, Methanobacteria and Thermoplasmata (Narihiro and Sekiguchi, 2007). Microbial community variations can influence the AD process and thereby inhibit or enhance the process. For example, it has been shown that the bio-augmentation of hydrogenotrophic methanogen (Methanoculleus bourgensis MS2T) in an anaerobic digester can play a significant role in overcoming ammonia inhibition (Fotidis et al., 2014). A shift in methanogenic pathways and methanogenic community composition has been observed when the microbial culture is exposed to increasing concentrations of acetate and ammonia (Fotidis et al., 2013), while specific bacteria such as the filamentous Microthrix or Nocardia have been shown to be associated with foaming incidents in biogas reactors (Kougias et al., 2014). A common feature of all these studies is that they provide a snapshot of microbial community composition and activity at a given time and in specific conditions. However, the response and development of microbial communities to external changes in process conditions, to date, has not been reported adequately in literature. This information is relevant to ensure smooth transitions when changing process operations or treating specific substrates. 
The main objective of this research was to study changes in the microbial population community as a response to variations in the operation of the AD process and co-digestion of urban organic waste (UOW) comprising food waste, grass clippings and garden waste with mixed sludge. This was achieved by: (i) analysing the composition of the microbial community during UOW codigestion in continuously stirred tank reactors (CSTRs), operated at sequentially reduced hydraulic retention times (HRTs), (ii) comparing two CSTRs fed with different UOW mixing ratios, cosewage sludge digestion, food waste, grass clippings and garden waste and (iii) analysing changes in the microbial population community in terms of relative abundance and diversity, and correlating these findings with reactor performance and operational process parameters.

\section{Materials and methods}

\subsection{Characterisation of input feedstock materials}

The feedstock materials included mixed sewage sludge, food waste, grass clippings and garden waste, which were collected from several locations in Denmark, as described in Fitamo et al. (2016a). The addition of UOW to existing AD operations at wastewater treatment plants (WWTPs) is able to boost biogas production, and current biogas reactor facilities at WWTPs can be used in this regard (Fitamo et al., 2016b). Organic feedstock was shredded into small particles with a shearshredder (ARP SC 2000) and knife mill (Wiencken 19225 and Fitzmill model D, Daso-6). Individual organic waste materials were then characterised in terms of physicochemical properties (e.g. total solids (TSs), volatile solids (VSs), total Kjeldahl nitrogen (TKN), lipids, VFAs, proteins, total $\mathrm{C}$ and total N). The analytical methods are described in Fitamo et al. (2016a).

\subsection{Experimental set up and operation}

The co-digestion experiment was conducted to maximise biogas production from UOW, by adding food and plant materials (garden waste and grass clippings) to existing sludge digestion at WWTPs. The laboratory experimental work was carried out in two CSTRs, named R1 and R2, each with a 
124

125

126

127

128

129

130

131

132

133

134

135

136

137

138

139

140

141

142

143

144

145

146

147

working volume of $7.5 \mathrm{~L}$. The temperature was kept constant in thermophilic conditions $\left(55^{\circ} \mathrm{C}\right)$ and with hot water circulation supplied by a circular closed heating system. The co-substrates were fed into the reactor via an automated feeding system, based on the organic loading rate (OLR) of the reactor. The set-up was equipped with an automated stirring system and a water displacement gasmetering counter to measure the amount of biogas produced. The CSTRs were operated in five distinctive operational phases. Phase I aimed at establishing a baseline performance relative to existing sewage sludge $\mathrm{AD}$, and it included the mono-digestion of $100 \%$ mixed sludge (primary and secondary sludge mixed at a 1:1 V/V ratio) in both R1 and R2, with a HRT of 30 days (HRT30). After Phase I, UOW was added to the mixed sludge and fed into the reactors in fixed percentage VS mixing ratios throughout Phases II to $\mathrm{V}$. Reactor R1 received 10:67:16:7 and reactor R2 received 10:44:32:14 of sewage sludge, food waste, grass clippings and garden waste, respectively. The ratios were set up in order to have high food waste in R1, while the VS share of food waste was reduced but the lignocellulosic garden and clippings feedstock doubled in R2. An overview of the experimental setup is provided in Table 1, which shows that the HRT was reduced stepwise, from 30 days (HRT30) in Phase II, to 20 days (HRT20) in Phase III, to 15 days (HRT15) in Phase IV and, finally, to 10 days (HRT10) in Phase V. Phases I, II, III, IV and V lasted for about 2.5, 1.9, 1.6, 2.8 and 2.5, respectively. Specific methane yield, productivity, concentrations of ammonia and acetate measured during the co-digestion of UOW in R1 and R2 are provided in Figure S-1 in the Supporting Information (SI) (Fitamo et al., 2016a).

$<$ Table 1 here>

\subsection{Sampling and DNA extraction}

Within each operational phase, duplicate reactor broth samples $(10 \mathrm{~mL})$ were taken from both reactors once steady-state conditions were reached - this amounted to 10 samples in total. Residual plant particles present in the samples were removed, using a $100 \mu \mathrm{m}$ nylon cell strainer 
148 filter. Centrifugation of the filtered samples (10,000 rpm, 10 minutes) was conducted to obtain $\sim 1.5$

$149 \mathrm{~g}$ of cell pellet. The total microbial DNA extraction (DNA isolation and purification) was

150 performed using the PowerSoil® DNA Isolation Kit protocol (MO BIO Laboratories, Carlsbad,

151 CA) with an additional initial cleaning step by Phenol:Chloroform:Isoamyl Alcohol 25:24:1 pH 8

152 (Sigma-Aldrich, DK). The quality of the purified DNA was examined with gel electrophoresis, and

153 the DNA concentration was analysed with NanoDrop 2000 (ThermoFisher Scientific, Waltham, 154 MA).

\subsection{S rRNA gene sequences}

156

157

158

159

160

161

162

163

164

165

The samples were sequenced by utilising the Illumina MiSeq platform at Ramaciotti Centre for Gene Function Analysis, University of New South Wales (Sydney, Australia), by amplifying the V4 hypervariable region of the $16 \mathrm{~S}$ ribosomal gene RNA using 515f-806r primers and following the protocol of the Earth Microbiome Project (Earth Microbiome, 2011). The raw Illumina sequence data obtained in this research work were submitted to the National Centre for Biotechnology Information's (NCBI) sequence read archive database (SRP078424) under the bio-project number (PRJNA328964). The sequences were analysed with CLC Genomic Workbench Software (V.8.0.2), equipped with a microbial genomics module plug-in as previously described (Kougias et al., 2016a). OTUs were aligned using MUSCLE software (Edgar RC, Nucleic Acids Res). The Maximum Likelihood Phylogenetic tree, Alpha diversity index and Beta diversity were computed as described by Kougias et al., (2016). The total number of reads obtained and total OTUs with corresponding taxonomy assignment for the microbial community in both R1 and R2 are reported in Table 1. OTUs with 10 sequences or fewer were considered extremely rare and were discarded from further analysis. Direct comparison of the microbial relative abundance between the samples was performed at genus and phylum level and was calculated as a percentage of the total community for each sample. 
The classification used to make the comparison of percentage relative abundance was

carried out with highly abundant (> $0.5 \%$ relative abundance) and lowly abundant (between $0.01 \%$ $0.5 \%$ of relative abundance) OTUs, whereas they were discarded from analysis when lower than $0.01 \%$. Most of the result and discussion section focuses on the most abundant microbes in the community (> $0.5 \%$ of relative abundance), while the less abundant microorganisms were considered only when statistically significant. Heat maps showing the relative abundance changes (fold changes), due to comparisons of different retention times and feedstock compositions, were prepared with the Multiexperiment viewer (MeV 4.9.0) (Saeed et al., 2003).

\subsection{Statistical analysis}

Statistics were performed using a general linear models analysis (GLM Procedure, SAS Institute, 2009). Firstly, differences in microbial abundance in the two reactors (R1 or R2) and in the subsequent phases (Phases I to Phase V) were studied in a series of single-trait analyses, including the reactor and the phase as effects and the abundance of each microorganism as a trait. Each microbial abundance was analysed separately with the GLM. The dataset for the analysis consisted in all the pairs of replicates sampled within each reactor during the different phases (data structure is reported in Table 1). In order to detect the trend of microbial abundance variation with respect to a change in HRT, the phase was alternatively included in the analysis as a linear, quadratic or cubic covariate. The model with the most significant shapes in variation (linear, quadratic or cubic; $\mathrm{P} \leq 0.05)$ for the phase effect was therefore chosen for each microbial abundance.

Methane yield, methane content of biogas, total VFA, individual VFAs, $\mathrm{pH}$, reactor productivity and ammonia were then used as traits to analyse variations in the operational process parameters. Reactor (R1 or R2) and phase (Phase I to V) were treated as fixed effects (e.g. traits were analysed by considering if they belonged to reactor R1 or R2, or to a specific Phase, I-V), and the abundance 
of each microorganism as a linear covariate. In this way, any variation in the operational process parameters was considered as depending on the variation in microbial abundance. Single-trait models were run, all including the same fixed factors (fixed) and each one considering different biochemical parameter; $i$ (parameter) as trait and a different microorganism; $k$ (microorganism) as covariate, that can be generalized as: parameter $_{i}=$ fixed + microorganism $_{k: i}$. This approach was used to avoid the over-parameterization of the model (i.e., to have too many parameters for the number of data), and to avoid problems of overlapping variances due to the introduction of microorganisms with similar variations in abundance in the same model.

\section{Results and discussion}

\subsection{General microbial community composition and diversity}

The phylogenetic composition of the most abundant bacteria and archaea (OTUs) in the entire microbial community was established, based on the 16S rRNA gene sequence considering all samples from both reactors in all of the considered phases (Figure 1). Between 90 and $96 \%$ of the OTUs were classified at the phylum level, showing that the majority of the microorganisms found in the reactors could be identified at the phylum level. In contrast, only $47-73 \%$ of the entire community was classified at the genus level (Table 1). This shows strong diversity among the samples. Further research, using advanced sequencing techniques, is needed to classify in detail any unknown microbes and to understand their specific role in the complex anaerobic degradation process.

\section{$<$ Figure 1 here >}

In general, the bacterial community consisted of Firmicutes, OP9, Synergistetes, Proteobacteria, Bacteroidetes, Thermotogae, Dicyoglomi and Chrloroflexi as the main phyla (Figure 1 and Figure S-2). The predominance of phylogenetic groups such as Firmicutes, Proteobacteria and Bacteroidetes was a result of their ability to degrade a wide range of substances 
221

222

223

224

225

such as cellulose, proteins, pectin and other xenobiotic compounds (Chouari et al., 2005; Zitomer et al., 2016). The only identified archaeal phylum was Euryarchaeota (Figure 1 and Figure S-3), which is a well-known microorganism involved in biogas production. These results are comparable to previous studies of dominant core microorganisms classified at the phylum level in biogas reactors (Luo et al., 2015; Nelson et al., 2011; Rivière et al., 2009b; Sundberg et al., 2013).

Microbial community diversity between different operational reactor phases was evaluated using principal coordinate analysis (PCoA), which assesses the similarities between the microbial community among samples. The results of the PCoA analysis are provided in Figure 2, showing that the samples were concentrated into four clusters corresponding to the individual operational phases of the reactors. For both reactors, the results clearly demonstrate a shift in microbial community diversity in accordance with changes in feedstock composition (AD of sewage sludge in Phase I to AD of UOW in Phase II) and the HRT of the reactors (Phase II-III). Similarities and differences between microbial community diversity in operational conditions could be explained with PCoA, which could capture $64 \%$ of the variation of microbial communities, indicated by PCo1 and $\mathrm{PCo} 2$ as $47 \%$ and $17 \%$, respectively.

During Phase I (100\% mixed sludge) of the AD operation, the samples examined for both R1 and R2 clustered closely when operating at HRT 30 days, as seen in Figure 2. In Phase II, microbial community diversity decreased according to the PCoA and the alpha diversity (Figure S4) in both reactors, most likely because of the introduction of UOW co-substrates to the reactors (the HRT of Phases I and II was the same at 30 days). This reduction in microbial community diversity between Phase I and Phase II could be due to the higher amount of lipids and proteins in the UOW in comparison to sewage sludge, thereby leading to inhibition of the microorganisms due to the accumulation of VFAs and an increase in ammonia concentration (Fotidis et al., 2013; Kougias et al., 2016b; Palatsi et al., 2010). It could also be the case that especially activated sludge also contains microorganisms from the WWTP process, i.e. aerobic microaerophilic and facultative 
microorganisms while urban organic waste consists of indigenous microbes (Favaro et al., 2013; Kim et al., 2009). The microbial biomass in the sludge would decrease as the share of the sludge is reduced in the co-digested feedstock. Moreover, the PCoA and alpha diversity showed that the decrease in microbial diversity was more pronounced in $\mathrm{R} 2$ than in $\mathrm{R} 1$, in connection with the fact that $\mathrm{R} 1$ received more food waste than $\mathrm{R} 2$, which instead was fed with a higher share of green waste containing lignocellulosic material. This shows that the slowly degradable feedstock in R2 resulted in lower microbial community diversity compared to the readily degradable feedstock in R1 (Figure 2 and Figure S-4) in Phase II (HRT30).

$<$ Figure 2 here >

Keeping the feedstock composition constant, a reduction in the HRT from 30 days (Phase II) to 20 days (Phase III) resulted in a shift in microbial community diversity (Figure 2) in both reactors. This result could be due to the adaption of microorganisms to the new co-substrate in the feedstock. However, microbial community diversity specifically increased in R2, when moving from Phase II to III (Figure S-4).

When reducing the HRT from 20 to 15 days (Phase III to Phase IV), R1 and R2 showed opposing behaviours (Figure 2), in that while R1 fed with food waste showed increased microbial diversity, R2 fed with lignocellulosic material developed a more specialised microbial community.

Finally, in Phase V, the AD processes were operated at a very low HRT (10 days) - a drastic condition that could lead to process instability and operational failure and bring the microbial community to a point of imbalance. In R1, microbial community diversity decreased significantly, indicating a wash out of non-adherent microbes responsible for food waste degradation (Figure S4), which are mainly present in the liquid part of the reactor. On the contrary, in R2, microbes related to lignocellulosic degradation and adhering to the substrate were more resistant to the wash out action. 


\subsection{Trends in microbial abundance variation}

271

272

273

274

275

276

277

278

279

280

281

282

283

284

285

286

287

288

289

The relative abundance of microbes (bacteria and archaea) for each operational phase (Phase I to $\mathrm{V}$ ) of R1 and R2 was provided in Figure 3. During Phase I, the most dominant microbes according to the taxonomy assignment at the phylum level were classified as Firmicutes (40-49\%), OP9 (11-13\%) and Synergistetes (7-10\%) in reactors R1 and R2 (Figure 3a). The relative abundance of Synergistetes and OP9 decreased in line with decreasing HRTs. Both Synergistetes and $O P 9$ are known to ferment organic compounds (carbohydrates, organic acids) and cellulose, sugars, hemicellulose, respectively, into $\mathrm{H}_{2}$ and acetate (Dodsworth et al., 2013).

$<$ Figure 3 here >

Other bacteria, such as Proteobacteria, were abundant (11\%) in Phase I (when the reactors were fed with sole-mixed sludge, MS), but they became undetectable when the reactors were fed with UOW co-substrates in Phase II, R1/30 and R2/30 (Figure 3a). Also, Dictyoglomi (1-5\%), EM3 (3-4\%) and Chloroflexi (1-2\%) disappeared when the substrate was changed from sludge to cosubstrate (Phase I to Phase II) (MS to R1/30 and R2/30, Figure 3a), because Chloroflexi especially is known to come with feedstock sludge and is mainly seen in sludge digestions. These microbes were favoured in Phase I (MS), possibly because of the sludge adapting to AD, but they were less favoured compared to other microbes in the AD of UOW (Phase II - V), which could be due to the reduction in the amount of sludge in the influent. Other studies have reported that Chloroflexi are frequently found in digested sludge taken from waste water treatment plants (Chouari et al., 2005; Rivière et al., 2009a; Yamada et al., 2005).

On the contrary, microorganisms belonging to Bacteroidetes were completely absent in Phase I (MS) and were observed with high relative abundance $(10.1 \%)$ in Phase II (R1/30 and $\mathrm{R} 2 / 30$, Figure $3 \mathrm{a}$ ) and sequentially increased during Phases II to $\mathrm{V}$ (R1/30 to R1/10 and R2/30 to $\mathrm{R} 2 / 10)$. During the AD of sludge in Phase I (MS), the relative abundance of Thermotogae at the 
phylum level was $1 \%$ in $\mathrm{R} 1$, but this increased in subsequent operational phases with corresponding values of 5\%, 20\%, 19\% and 30\% for Phases II (R1/30), III (R1/20), IV (R1/15) and V (R1/10), respectively (Figure 3a). Microorganisms belonging to Thermotogae are known as hydrogenproducing bacteria and produce acetate and $\mathrm{CO}_{2}$ as by-products from biomass and organic waste fermentation in thermophilic conditions. Similarly, an increasing trend in the relative abundance of Thermotogae was observed in $\mathrm{R} 2(\mathrm{R} 2 / 30$ to $\mathrm{R} 2 / 10)$.

Regarding the archaeal community, methane-producing hydrogenotrophic Methanothermobacter and Methanosarcina were the predominant and core taxa throughout the experiment (Figures $3 \mathrm{~b}$ and 3c), indicating that archaea are more independent than bacteria in response to different feedstock compositions. Generally, from Phase I (MS) to Phase II (R1/30 and R2/30), the relative abundance of Euryarchaeota increased from $2 \%$ to $9 \%$ and $7 \%$ in R1 (R1/30) and R2 (R2/30), respectively (Figure 3a). On the contrary, they decreased in abundance from $3 \%$ to $0.5 \%$ (by a factor of 5) and by $6 \%$ to $0.3 \%$ (by a factor of 9 ) in R1 (from R1/15 to R1/10) and R2 (from R2/15 to R2/10) when the HRT was changed from HRT15 (Phase IV) to HRT10 (Phase V) (Figure 3a), thus indicating that archaea are more dependent on HRT than on feed composition. In both reactors (R1 and R2), a considerable decrease in methane yield was also observed when the HRT was changed from 15 days to 10 days as seen in Figure S-1 (SI), which may be due to overloading or washout of Euryarchaeota.

In all phases, relative abundance of Methanothermobacter remained constant except in Phase V (HRT10), where abundance decreased (Figure 3c, R1/10 and R2/10). The relative abundance of Methanosarcina increased dramatically at HRT10 (Phase V, R1/10 and R2/10) (Figure 3c). The genus Methanosarcina provides metabolic capability in both acetoclastic and hydrogenotrophic methanogenesis and has also been reported to be more favourable in elevated ammonia and VFA concentrations (Calli, 2005; De Vrieze et al., 2012; Staley et al., 2011). 


\subsection{Influence of different parameters on AD microbial community composition}

\subsubsection{The effect of feedstock composition}

The percentage of relative microbial abundance considered in each reactor (R1 and R2) and in the different phases (Phases I to Phase V), averaged for the replicates, is shown in a heat map and also includes the fold changes of the most abundant microorganism in a steady-state condition in R1 and R2 (Figure 4). GLM analysis provided information about the significant variation in microbial abundance, due to the different UOW feedstock compositions, and to the operational phase. The core dominant genera found in both reactors were Thermonema, $S 1$ ( $\mathrm{P} \leq 0.001)$, Anaerobaculum $(\mathrm{P} \leq 0.05)$, Coprothermobacter and Methanothermobacter, as seen in Figure 4 and Figure S-5 (SI). Species belonging to Coprothermobacter were identified as proteolytic anaerobic thermophilic microbes in the biogas reactors and also established syntrophy with hydrogenotrophic methanogens (Gagliano et al., 2015). Moreover, it is known that members of Bacteroides play a significant role in cellulose, fats and proteins degradation (Hatamoto et al., 2007; Li et al., 2013). Meanwhile, Anaerobaculum was found for the fermentation of organic acids and carbohydrates into acetate, hydrogen and $\mathrm{CO}_{2}$ (Menes and Muxí, 2002).

$<$ Figure 4 here >

Limited numbers of significant variations were found between the reactors fed with different UOW co-substrate compositions (Figure 4). Among the most abundant microbes $(>0.5 \%$ relative abundance), three OTUs classified as Anaerobaculum, Thermacetogenium and Ruminococcaceae were significantly more abundant (two to three times) in $\mathrm{R} 2$ compared to $\mathrm{R} 1 \quad \mathrm{P} \leq 0.05)$. Thermacetogenium is a thermophilic syntrophic acetate oxidising bacterium and has also been identified in the AD of kraft-pulp wastewater (Hattori, 2000). This finding confirmed that the methane production pathway was favoured by syntrophic acetate oxidation (hydrogenotrophic methanogens) in UOW co-digestion. 
Other microbes, with a percentage relative abundance less than $0.5 \%$, were significantly

343 enriched in R2 and belonged to Porphyromonadaceae (11 times more abundant in R2) and

344 Clostridium (three times more abundant in $\mathrm{R} 2 ; \mathrm{P} \leq 0.01$ ). Members of the Clostridium genus are

345 known to degrade complex cellulose biopolymers (Guo et al., 2015; Nelson et al., 2011) and

346 lignocellulosic material components (Cirne et al., 2007; O’Sullivan et al., 2005).

S1 (Thermotogales) and Thermonema, (relative abundance (>0.5\%) decreased significantly in R2 compared to $\mathrm{R} 1 \quad(\mathrm{P} \leq 0.05)$ by a factor of 2 and 1.3 , respectively (Figure 4). Thermotogales microorganisms are involved in the fermentation of substrates such as glucose, acetate, methanol and starch as well as reducing elemental sulphur and sulphate (Balk et al., 2002; Feng et al., 2010). R1 was enriched with carbohydrate and fat-degrading microorganisms of Lactobacillus (5 times; $\mathrm{P} \leq 0.05$ ) (Li et al., 2013). Other less abundant OTUs, such as Exiguobacterium, Bacillus and Allochromatium, decreased in R2 compared to R1 by a factor of 6.4 and 6, respectively (Figure 4). The rest of the microorganisms, apart from Caldicoprobacter $(\mathrm{P} \leq 0.05)$, were found in both $\mathrm{R} 1$ and $\mathrm{R} 2$, irrespective of the feedstock.

\subsubsection{The effect of HRT}

Differences in microbial relative abundance, due to hydraulic retention times, were detected by considering the effect of the operational phases on the abundance of each microbe. Figure 4 and Figure 5, respectively reports the abundances of microbial communities in the two reactors in the different phases and the changes in the relative abundance of microorganisms between phases. Microbes related to the fermentation of sugars into acetate, lactate, ethanol, $\mathrm{CO}_{2}$ and $\mathrm{H}_{2}$, such as Thermonema, S1 and Caldicoprobacter (Bouanane-Darenfed et al., 2011), syntrophic acetate oxidiser, such as Thermacetogenium (Hattori, 2000), and Lactobacillus increased by a factor of at least seven (Figure 5). The GLM analysis (Figure 5) showed a significant trends for these microorganisms, either linear (Thermonema; $\mathrm{P} \leq 0.01$ ), quadratic (i.e. roughly assumed the shape of a curve: Caldicoprobacter, Thermacetogenium; $\mathrm{P} \leq 0.001$ ), or cubic (i.e. showing an inflection point: 
367

368

369

370

371

372

373

374

375

376

377

379

380

381

382

383

Lactobacillus; P $\leq 0.05$ ). At HRT10 (Phase V) the community populations of Caldicoprobacter,

Thermacetogenium and Lactobacillus decreased in abundance (SI: Figure S-5), except those of Thermonema and $S 1$ (Figure 6), which may be due to process inhibition resulting in a yield and methane productivity drop.

$<$ Figure 5 here >

The relative abundance of Acinetobacter, Solibacillus, Dictyoglomus, Proteiniclasticum, Exiguobacterium, Fervidobacterium, Bacillus, Allochromatium and SMB53 decreased by a factor of at least three in subsequent phases compared to Phase I (Figure 5 and Figure S-5 (SI)). The trend of Dictyoglomus was linear $(\mathrm{P} \leq 0.01)$, The shape of variation for Solibacillus and Proteiniclasticum was mainly linear $(\mathrm{P} \leq 0.05)$, but also a quadratic component was close to significance $(\mathrm{P}=0.06)$. The other microorganisms had a mixed pattern of variation, with both linear and quadratic significant components $(\mathrm{P} \leq 0.05)$.

$<$ Figure 6 here >

During the $\mathrm{AD}$ process of Phase II to Phase V, OTUs members of Fervidobacterium, Bacillus, Allochromatium and SMB53 decreased in abundance, as shown in Figure 6 and Figure S-5 (SI). The most dominant genera in Phases II, III and IV at HRT30, HRT20 and HRT15, respectively, were simple and complex sugar-fermenting bacteria (S1), proteolitic microorganisms (Coprothermobacter), organic acid-degrading bacteria (Anaerobaculum), Methanothermobacter and Thermonema ((Figure 6 and Figure S-5 (SI)). This could be due to increased OLR of UOW in the feedstock. Additionally, Figure 5 shows an increasing trend of the dominant bacterial community, S1 and Thermonema, which could be due to higher specific growth rates surviving washouts at shorter HRTs, and of a taxon belonging to Firmicutes (order MBA08; Figure S-2), another taxon among the most representative. An almost decreasing trend of Anaerobaculum and Coprothermobacter with respect to HRT, except for the last phase (HRT10), was also noted. The 
391

392

393

394

395

396

methane-producing microorganism, namely Methanothermobacter, remained constant at HRT20 and HRT15 but dropped at HRT10.

\subsection{Biochemical correlation of the microbial community with AD process parameters}

The proper functioning of the $\mathrm{AD}$ process is influenced by a number of intertwined microorganisms governing the complex biochemical pathways. Performance parameters measured in the reactors, such as specific methane yield, methane productivity, ammonia concentration and acetate (SI: Figure S-1) (reported in Fitamo et al., 2016a), were correlated with OTUs abundance. The GML analysis (Table S-1, SI) produced a coefficient of linear regression for each biochemical parameter-microbial abundance pair: a positive coefficient indicated that an increase in targeted microbial abundance also caused an increase in the biochemical parameter under consideration, whereas a negative coefficient indicated a decrease in the biochemical parameter, due to an increase in microbial abundance (Table 2 and Table S-1). When comparing microbial community composition with AD performance parameters (Figure S-1,SI), methane yield and productivity significantly increased $(\mathrm{P} \leq 0.05$; Table 2$)$ when an increase in abundance variation occurred for the OTUs assigned to Proteobacteria (Acinetobacter iwoffii, OTU: 532569; Allochromatium), Thermotogae (S1, Fervidobacterium, two OTUs) and Bacteroidetes (Thermonema). On the other hand, a significant decrease $(\mathrm{P} \leq 0.05$; Table 2$)$ in methane productivity and yield was observed following an increase in the abundance of Dictyoglomus, Fervidobacterium (two OTUs) and in the OTU 573124 belonging to Acinetobacter. Moreover, methane productivity and yield were significantly affected by the abundance of microorganisms belonging to the phylum Firmicutes (Coprothermobacter, Syntrophomonas, Clostridium, Proteiniclasticum, Exiguobacterium, Bacillus, 
415

416

417

418

419

420

421

422

423

424

425

two OTUs including Bacillus muralis, Solibacillus and SMB53), which is mostly involved in the hydrolysis of complex organic matter. Variation in the methane percentage was instead significantly affected $(\mathrm{P} \leq 0.001)$ only by abundance of the OTU belonging to the phylum Chloroflexi, class Anaerolineae, even if relatively low in abundance $(\mathrm{P}<0.05)$ (Table $\mathrm{S}-1)$, members of which may be thermophilic or mesophilic, are generally ubiquitous and play an important role in the environment (Yamada et al., 2006).

Considering the VFAs, a significant decrease in the abundance of these acids $(\mathrm{P} \leq 0.001$; Table 2), in particular in propionate $(\mathrm{P} \leq 0.05$; Table 2$)$, was related to an increase in Syntrophomonas (OTU: 1110842), known to beta-oxidise saturated fatty acids to acetate or acetate and propionate (Sieber, 2010). Propionate significantly decreased ( $\mathrm{P} \leq 0.01$; Table $\mathrm{S}-1)$ following an increase in OTU 254504 belonging to the order SHA-98 of the class Clostridia, phylum Firmicutes, known to be involved in syntrophic acetate oxidation activities. The concentration of acetate followed the same trend $(\mathrm{P} \leq 0.05)$ for methane yield and production, apart for $S 1(\mathrm{P}=0.013$; Table 2). Acetate also significantly increased when Methanosarcina increased $(\mathrm{P}<0.01$; Table 2$)$ and seemed also to be significantly associated with the phylum Firmicutes (Coprothermobacter, Syntrophomonas, Clostridium, Solibacillus), and with Methanosarcina, OTU positively correlated with acetoclastic methanogens, because acetate is a substrate for Methanosarcina metabolism. On the other hand, acetate variation was not related to variation in the hydrogenotrophic methanogen Methanothermobacter thermautotrophicus, since methane is mainly produced via syntrophic acetate oxidation association followed by hydrogenotrophic methanogenesis. Butyrate, the last VFA considered in this study, resulted significantly in the abundance of Syntrophomonas, OTU 203894 and Anaerobaculum (phylum Synergistetes, OTU 533824; $\mathrm{P} \leq 0.001$, Table 2), a genus able to reduce substrates to butyrate with glucose as an electron donor.

The increase in Anaerobaculum abundance ( $\mathrm{P} \leq 0.01$; Table 2$)$ was also related to a decrease in the concentration of ammonia. Moreover, ammonia concentration increased in relation to the 
440

441

442

443

444

445

446

447

448

449

450

451

452

453

454

455

456

457

458

459

460

461

462

increase in Syntrophomonas, OTU 203894, able to convert atmospheric molecular nitrogen to ammonia (Sieber, 2010). pH variation was only affected by an OTU assigned to Clostridium (Table 2), whereby an increase in abundance was related to an increase in $\mathrm{pH}(\mathrm{P} \leq 0.001)$, and by some other non-abundant Firmicutes OTUs (Table S-1). Table S-1 (SI), providing an overview of the less abundant OTUs significantly correlated with $\mathrm{AD}$ performance parameters, showed that biogas production process was affected not only by dominant microorganisms, but also by less abundant but crucial microorganisms.

Overall, the results of the microbial community analysis show that the composition of feedstock and the process condition affects the diversity of the microbial community. The biochemical correlation also reveals that certain groups of microbes particularly hydrolytic bacteria are significantly correlated with anaerobic digestion process performance parameters. Knowledge of changes in microbial community structures as a response changes in feedstock composition, operational process parameter and reactor performance could help wastewater treatment plants and biogas plant to enhance the methane yield and productivity through bioaugmentation.

\section{Conclusion}

The dominant microbial community, Proteobacteria, observed in sludge-based monodigestion decreased in abundance compared to the anaerobic co-digestion of urban organic waste (UOW). Nevertheless, a new community, Thermonema, increased during the co-digestion of UOW.

Complex organic polymer degraders Thermacetogenium, Anaerobaculum, Ruminococcaceae and Clostridium were significantly abundant in reactor fed with high share of lignocellulosic material (R2) however S1, Thermonema and Lactobacillus were found to be significantly abundant in reactor fed with high share of food waste (R1). The relative abundance of 
463

464

465

466

467

468

469

470

471

472

473

474

475

476

477

478

479

480

481

482

483

484

485

486

S1 and Thermonema increased, while other taxa such as Coprothermobacter, Anaerobaculum and

Dictyoglomus decreased in line with sequentially decreased HRTs.

Syntrophic acetate oxidation, followed by hydrogenotrophic methanogenesis, was established as the main methane formation pathway in both R1 and R2. However, the relative abundance of methanogenic Euryarchaeota (Methanothermobacter) decreased when the HRT was changed from 15 to 10 days, in which case Methanosarcina became dominant. Methane yield was correlated with several Firmicutes (Coprothermobacter, Syntrophomonas, Clostridium) involved in the hydrolysis stage. The concentration of acetate was correlated with several OTUs, such as Methanosarcina and Acinetobacter iwoffii, while the concentration of ammonia was associated with Anaerobaculum and Syntrophomonas.

The particular microbial community composition and diversity of the corresponding feedstock composition and operational parameters could support biogas plants to enhance the anaerobic digestion process performance by using bioaugmentation of the respective microorganisms to achieve rapid microbial adaptation and also optimal production of methane yield and productivity.

\section{Acknowledgments}

The project was supported by the Danish Council for Strategic Research (DSF) under the "Strategic Research in Sustainable Energy and Environment" research programme through the project "Optimisation of value chains for biogas production in Denmark (BioChain)" (Project no. 12132631). Moreover, the DSF project (Symbio) (Project ID no: 12-132654) supported the research. The author would like to thank Xinyu Zhu (PhD student at DTU Environment, Denmark). The authors are responsible for the content of this publication. 
493

494

495

496

497

498

499

500

501

502

503

504

505

506

507

508

509

510

511

512

513

514

515

516

517

\section{References}

Angelidaki, I., Ellegaard, L., Ahring, B., 1999. A comprehensive model of anaerobic bioconversion of complex substrates to biogas. Biotechnol. Bioeng. 63, 363-372. doi:10.1002/(SICI)10970290(19990505)63:33.0.CO;2-Z

Appels, L., Baeyens, J., Degrève, J., Dewil, R., 2008. Principles and potential of the anaerobic digestion of waste-activated sludge. Prog. Energy Combust. Sci. 34, 755-781. doi:10.1016/j.pecs.2008.06.002

Balk, M., Weijma, J., Stams, A.J.M., 2002. Thermotoga lettingae sp. nov., a novel thermophilic, methanol-degrading bacterium isolated from a thermophilic anaerobic reactor. Int. J. Syst. Evol. Microbiol. 52, 1361-8. doi:10.1099/00207713-52-4-1361

Bhat, M.K., Bhat, S., 1997. Cellulose degrading enzymes and their potential industrial applications. Biotechnol. Adv. 15, 583-620. doi:10.1016/S0734-9750(97)00006-2

Bouanane-Darenfed, A., Fardeau, M.-L., Grégoire, P., Joseph, M., Kebbouche-Gana, S., Benayad, T., Hacene, H., Cayol, J.-L., Ollivier, B., 2011. Caldicoprobacter algeriensis sp. nov. a new thermophilic anaerobic, xylanolytic bacterium isolated from an Algerian hot spring. Curr. Microbiol. 62, 826-32. doi:10.1007/s00284-010-9789-9

Calli, B., 2005. Community changes during start-up in methanogenic bioreactors exposed to increasing levels of ammonia. Environ. Technol. 26, 85-91.

Campanaro, S., Treu, L., Kougias, P.G., De Francisci, D., Valle, G., Angelidaki, I., 2016a. Metagenomic analysis and functional characterization of the biogas microbiome using high throughput shotgun sequencing and a novel binning strategy. Biotechnol. Biofuels 9, 26. doi:10.1186/s13068-016-0441-1

Campanaro, S., Treu, L., Kougias, P.G., Francisci, D. De, Valle, G., 2016b. Biotechnology for Biofuels Metagenomic analysis and functional characterization of the biogas microbiome using high throughput shotgun sequencing and a novel binning strategy. Biotechnol. Biofuels 1-17. 
doi:10.1186/s13068-016-0441-1

Chen, Y., Cheng, J.J., Creamer, K.S., 2008. Inhibition of anaerobic digestion process: a review. Bioresour. Technol. 99, 4044-64. doi:10.1016/j.biortech.2007.01.057

Chouari, R., Le Paslier, D., Daegelen, P., Ginestet, P., Weissenbach, J., Sghir, A., 2005. Novel predominant archaeal and bacterial groups revealed by molecular analysis of an anaerobic sludge digester. Environ. Microbiol. 7, 1104-15. doi:10.1111/j.1462-2920.2005.00795.x

Cirne, D.G., Lehtomäki, A., Björnsson, L., Blackall, L.L., 2007. Hydrolysis and microbial community analyses in two-stage anaerobic digestion of energy crops. J. Appl. Microbiol. 103, 516-27. doi:10.1111/j.1365-2672.2006.03270.x

De Vrieze, J., Hennebel, T., Boon, N., Verstraete, W., 2012. Methanosarcina: the rediscovered methanogen for heavy duty biomethanation. Bioresour. Technol. 112, 1-9. doi:10.1016/j.biortech.2012.02.079

Dodsworth, J.A., Blainey, P.C., Murugapiran, S.K., Swingley, W.D., Ross, C.A., Tringe, S.G., Chain, P.S.G., Scholz, M.B., Lo, C.-C., Raymond, J., Quake, S.R., Hedlund, B.P., 2013. Single-cell and metagenomic analyses indicate a fermentative and saccharolytic lifestyle for members of the OP9 lineage. Nat. Commun. 4, 1854. doi:10.1038/ncomms2884

Earth Microbiome, P., 2011. 16S Illumina Amplicon Protocol : Earth Microbiome Project [WWW Document]. URL http://www.earthmicrobiome.org/emp-standard-protocols/16s/ (accessed 1.1.16).

Eikmeyer, F.G., Rademacher, A., Hanreich, A., Hennig, M., Jaenicke, S., Maus, I., Wibberg, D., Zakrzewski, M., Pühler, A., Klocke, M., Schlüter, A., 2013. Detailed analysis of metagenome datasets obtained from biogas-producing microbial communities residing in biogas reactors does not indicate the presence of putative pathogenic microorganisms. Biotechnol. Biofuels 6, 49. doi:10.1186/1754-6834-6-49

Favaro, L., Alibardi, L., Lavagnolo, M.C., Casella, S., Basaglia, M., 2013. Effects of inoculum and 
indigenous microflora on hydrogen production from the organic fraction of municipal solid waste. Int. J. Hydrogen Energy 38, 11774-11779. doi:10.1016/j.ijhydene.2013.06.137

Feng, Y., Cheng, L., Zhang, X., Li, X., Deng, Y., Zhang, H., 2010. Thermococcoides shengliensis gen. nov., sp. nov., a new member of the order Thermotogales isolated from oil-production fluid. Int. J. Syst. Evol. Microbiol. 60, 932-7. doi:10.1099/ijs.0.013912-0

Fitamo, T., Boldrin, A., Boe, K., Angelidaki, I., Scheutz, C., 2016a. Co-digestion of food and garden waste with mixed sludge from wastewater treatment in continuously stirred tank reactors. Bioresour. Technol. 206, 245-254. doi:10.1016/j.biortech.2016.01.085

Fitamo, T., Boldrin, A., Dorini, G., Boe, K., Angelidaki, I., Scheutz, C., 2016b. Optimising the anaerobic co-digestion of urban organic waste using dynamic bioconversion mathematical modelling. Water Res. 106, 283-294. doi:10.1016/j.watres.2016.09.043

Fotidis, I.A., Karakashev, D., Kotsopoulos, T.A., Martzopoulos, G.G., Angelidaki, I., 2013. Effect of ammonium and acetate on methanogenic pathway and methanogenic community composition. FEMS Microbiol. Ecol. 83, 38-48. doi:10.1111/j.1574-6941.2012.01456.x

Fotidis, I.A., Wang, H., Fiedel, N.R., Luo, G., Karakashev, D.B., Angelidaki, I., 2014. Bioaugmentation as a solution to increase methane production from an ammonia-rich substrate. Environ. Sci. Technol. 48, 7669-76. doi:10.1021/es5017075

Gagliano, M.C., Braguglia, C.M., Petruccioli, M., Rossetti, S., 2015. Ecology and biotechnological potential of the thermophilic fermentative Coprothermobacter spp. FEMS Microbiol. Ecol. 91. doi:10.1093/femsec/fiv018

Gerardi, M.H., 2003. The Microbiology of Anaerobic Digesters, Wastewater Microbiology Series. John Wiley \& Sons, Inc., Hoboken, NJ, USA. doi:10.1002/0471468967

Goux, X., Calusinska, M., Fossépré, M., Benizri, E., Delfosse, P., 2016. Start-up phase of an anaerobic full-scale farm reactor - Appearance of mesophilic anaerobic conditions and establishment of the methanogenic microbial community. Bioresour. Technol. 212, 217-26. 
doi:10.1016/j.biortech.2016.04.040

Guo, J., Peng, Y., Ni, B.-J., Han, X., Fan, L., Yuan, Z., 2015. Dissecting microbial community structure and methane-producing pathways of a full-scale anaerobic reactor digesting activated sludge from wastewater treatment by metagenomic sequencing. Microb. Cell Fact. 14, 33. doi:10.1186/s12934-015-0218-4

Haruta, S., Cui, Z., Huang, Z., Li, M., Ishii, M., Igarashi, Y., 2002. Construction of a stable microbial community with high cellulose-degradation ability. Appl. Microbiol. Biotechnol. 59, 529-34. doi:10.1007/s00253-002-1026-4

Hatamoto, M., Imachi, H., Ohashi, A., Harada, H., 2007. Identification and cultivation of anaerobic, syntrophic long-chain fatty acid-degrading microbes from mesophilic and thermophilic methanogenic sludges. Appl. Environ. Microbiol. 73, 1332-40. doi:10.1128/AEM.02053-06

Hattori, S., 2000. Thermacetogenium phaeum gen. nov., sp. nov., a strictly anaerobic, thermophilic, syntrophic acetate-oxidizing bacterium. Int. J. Syst. Evol. Microbiol. 50 Pt 4.

Hayashi, H., Takehara, M., Hattori, T., Kimura, T., Karita, S., Sakka, K., Ohmiya, K., 1999. Nucleotide sequences of two contiguous and highly homologous xylanase genes xynA and xynB and characterization of XynA from Clostridium thermocellum. Appl. Microbiol. Biotechnol. 51, 348-357. doi:10.1007/s002530051401

Kim, D.-H., Kim, S.-H., Shin, H.-S., 2009. Hydrogen fermentation of food waste without inoculum addition. Enzyme Microb. Technol. 45, 181-187. doi:10.1016/j.enzmictec.2009.06.013

Kougias, P.G., Francisci, D. De, Treu, L., Campanaro, S., Angelidaki, I., 2014. Bioresource Technology Microbial analysis in biogas reactors suffering by foaming incidents. Bioresour. Technol. 167, 24-32. doi:10.1016/j.biortech.2014.05.080

Kougias, P.G., Treu, L., Benavente, D.P., Boe, K., Campanaro, S., Angelidaki, I., 2016a. Ex-situ biogas upgrading and enhancement in different reactor systems. Bioresour. Technol. doi:10.1016/j.biortech.2016.11.124 
593

594

595

596

597

598

599

600

601

602

603

604

605

606

607

608

609

610

611

612

613

614

615

616

617

Kougias, P.G., Treu, L., Campanaro, S., Zhu, X., Angelidaki, I., 2016b. Dynamic functional characterization and phylogenetic changes due to Long Chain Fatty Acids pulses in biogas reactors. Sci. Rep. 6, 28810. doi:10.1038/srep28810

Li, A., Chu, Y., Wang, X., Ren, L., Yu, J., Liu, X., Yan, J., Zhang, L., Wu, S., Li, S., 2013. A pyrosequencing-based metagenomic study of methane-producing microbial community in solid-state biogas reactor. Biotechnol. Biofuels 6, 3. doi:10.1186/1754-6834-6-3

Lin, Q., De Vrieze, J., Li, J., Li, X., 2016. Temperature affects microbial abundance, activity and interactions in anaerobic digestion. Bioresour. Technol. 209, 228-236. doi:10.1016/j.biortech.2016.02.132

Luo, G., De Francisci, D., Kougias, P.G., Laura, T., Zhu, X., Angelidaki, I., 2015. New steady-state microbial community compositions and process performances in biogas reactors induced by temperature disturbances. Biotechnol. Biofuels 8, 3. doi:10.1186/s13068-014-0182-y

Lynd, L.R., Weimer, P.J., van Zyl, W.H., Pretorius, I.S., 2002. Microbial Cellulose Utilization: Fundamentals and Biotechnology. Microbiol. Mol. Biol. Rev. 66, 506-577. doi:10.1128/MMBR.66.3.506-577.2002

Mao, C., Feng, Y., Wang, X., Ren, G., 2015. Review on research achievements of biogas from anaerobic digestion. Renew. Sustain. Energy Rev. 45, 540-555. doi:10.1016/j.rser.2015.02.032

Mata-Alvarez, J., Dosta, J., Romero-Güiza, M.S., Fonoll, X., Peces, M., Astals, S., 2014. A critical review on anaerobic co-digestion achievements between 2010 and 2013. Renew. Sustain. Energy Rev. 36, 412-427. doi:10.1016/j.rser.2014.04.039

Mata-Alvarez, J., Macé, S., Llabrés, P., 2000. Anaerobic digestion of organic solid wastes. An overview of research achievements and perspectives. Bioresour. Technol. 74, 3-16. doi:10.1016/S0960-8524(00)00023-7

Menes, R.J., Muxí, L., 2002. Anaerobaculum mobile sp. nov., a novel anaerobic, moderately thermophilic, peptide-fermenting bacterium that uses crotonate as an electron acceptor, and 
618

619

620

621

622

623

624

625

626

627

628

629

630

631

632

633

634

635

636

637

638

639

640

641

642

emended description of the genus Anaerobaculum. Int. J. Syst. Evol. Microbiol. 52, 157-64. doi:10.1099/00207713-52-1-157

Narihiro, T., Sekiguchi, Y., 2007. Microbial communities in anaerobic digestion processes for waste and wastewater treatment: a microbiological update. Curr. Opin. Biotechnol. 18, 273-8. doi:10.1016/j.copbio.2007.04.003

Nelson, M.C., Morrison, M., Yu, Z., 2011. A meta-analysis of the microbial diversity observed in anaerobic digesters. Bioresour. Technol. 102, 3730-9. doi:10.1016/j.biortech.2010.11.119

O’Sullivan, C.A., Burrell, P.C., Clarke, W.P., Blackall, L.L., 2005. Structure of a cellulose degrading bacterial community during anaerobic digestion. Biotechnol. Bioeng. 92, 871-8. doi:10.1002/bit.20669

Palatsi, J., Illa, J., Prenafeta-Boldú, F.X., Laureni, M., Fernandez, B., Angelidaki, I., Flotats, X., 2010. Long-chain fatty acids inhibition and adaptation process in anaerobic thermophilic digestion: batch tests, microbial community structure and mathematical modelling. Bioresour. Technol. 101, 2243-51. doi:10.1016/j.biortech.2009.11.069

Pöschl, M., Ward, S., Owende, P., 2010. Evaluation of energy efficiency of various biogas production and utilization pathways. Appl. Energy 87, 3305-3321. doi:10.1016/j.apenergy.2010.05.011

Rivière, D., Desvignes, V., Pelletier, E., Chaussonnerie, S., Guermazi, S., Weissenbach, J., Li, T., Camacho, P., Sghir, A., 2009a. Towards the definition of a core of microorganisms involved in anaerobic digestion of sludge. ISME J. 3, 700-14. doi:10.1038/ismej.2009.2

Rivière, D., Desvignes, V., Pelletier, E., Chaussonnerie, S., Guermazi, S., Weissenbach, J., Li, T., Camacho, P., Sghir, A., 2009b. Towards the definition of a core of microorganisms involved in anaerobic digestion of sludge. ISME J. 3, 700-714. doi:10.1038/ismej.2009.2

Saeed, A.I., Sharov, V., White, J., Li, J., Liang, W., Bhagabati, N., Braisted, J., Klapa, M., Currier, T., Thiagarajan, M., Sturn, A., Snuffin, M., Rezantsev, A., Popov, D., Ryltsov, A., 
643

644

645

646

647

648

649

650

651

652

653

654

655

656

657

658

659

660

661

662

663

664

665

666

667

Kostukovich, E., Borisovsky, I., Liu, Z., Vinsavich, A., Trush, V., Quackenbush, J., 2003.

TM4: a free, open-source system for microarray data management and analysis. Biotechniques 34, 374-8.

Sieber, J.R., 2010. The genome of Syntrophomonas wolfei: new insights into syntrophic metabolism and biohydrogen production. Environ. Microbiol. 12, 2289-2301.

Staley, B.F., de Los Reyes, F.L., Barlaz, M.A., 2011. Effect of spatial differences in microbial activity, $\mathrm{pH}$, and substrate levels on methanogenesis initiation in refuse. Appl. Environ. Microbiol. 77, 2381-91. doi:10.1128/AEM.02349-10

Sundberg, C., Al-Soud, W.A., Larsson, M., Alm, E., Yekta, S.S., Svensson, B.H., Sørensen, S.J., Karlsson, A., 2013. 454 pyrosequencing analyses of bacterial and archaeal richness in 21 fullscale biogas digesters. FEMS Microbiol. Ecol. 85, 612-26. doi:10.1111/1574-6941.12148

Weiland, P., 2010. Biogas production: Current state and perspectives. Appl. Microbiol. Biotechnol. 85, 849-860. doi:10.1007/s00253-009-2246-7

Yamada, T., Sekiguchi, Y., Hanada, S., Imachi, H., Ohashi, A., Harada, H., Kamagata, Y., 2006. Anaerolinea thermolimosa sp. nov., Levilinea saccharolytica gen. nov., sp. nov. and Leptolinea tardivitalis gen. nov., sp. nov., novel filamentous anaerobes, and description of the new classes Anaerolineae classis nov. and Caldilineae classis nov. in the . Int. J. Syst. Evol. Microbiol. 56, 1331-40. doi:10.1099/ijs.0.64169-0

Yamada, T., Sekiguchi, Y., Imachi, H., Kamagata, Y., Ohashi, A., Harada, H., 2005. Diversity, localization, and physiological properties of filamentous microbes belonging to Chloroflexi subphylum I in mesophilic and thermophilic methanogenic sludge granules. Appl. Environ. Microbiol. 71, 7493-503. doi:10.1128/AEM.71.11.7493-7503.2005

Zitomer, D., Maki, J., Venkiteshwaran, K., Bocher, B., 2016. Relating Anaerobic Digestion Microbial Community and Process Function. Microbiol. Insights 8, 37. doi:10.4137/MBI.S33593 


\section{List of Figures}

Figure 1: Phylogenetic trees of OTUs, describing the entire microbial community observed in both reactors ( $\mathrm{R} 1$ and $\mathrm{R} 2$ ) during the $\mathrm{AD}$ of mixed sludge and co-digestion of urban organic waste at $55^{\circ} \mathrm{C}$ and HRTs of 30, 20, 15 and 10 days. The letter $\mathrm{k}_{-}$denotes kingdom, $\mathrm{p}_{-}$(phylum), c_(class), $\mathrm{o}_{-}$(order), $\mathrm{f}_{-}$(family), g_ (genus) and s_ (species) taxonomical levels. Thick branches indicate bootstrap analysis values higher than 50 .

Figure 2: Differences in microbial community diversity shown by principal coordinate analysis ordination (PCoA), considering differences in hydraulic retention time (Phases I to V) and feedstock composition (R1 and R2). The diamond shapes indicate the AD process in R1, while the circles represent $\mathrm{R} 2$. The arrows indicate changes in microbial composition.

Figure 3: The relative abundance of microorganisms based on the taxonomical classification of the microbial community in both reactors (R1 and R2) in each operational phase (Phase I to V) (a) identified at phylum, (b) identified at genus level ( $>0.5$ OTUs of relative abundance) and (c) archaeal community at genus level (> 0.5 OTUs ). All other unidentified OTUs were included in "Unclassified". The letter MS denotes sole mixed sludge at HRT of 30 days (Phase I), the numbers 30 (Phase II), 20 (Phase III), 15 (Phase IV) and 10 (Phase V) denotes the hydraulic retention times at the respective reactors ( $\mathrm{R} 1$ and $\mathrm{R} 2)$.

Figure 4: The heat map of the average relative abundance of replicates of dominant microorganisms in the different phases (Phase I to Phase V) within R1 and R2 (on the left panel), and fold changes $\left(\log _{2}(\mathrm{R} 1 / \mathrm{R} 2)\right)$ from R1 to R2 (on the right panel). Colour scales are shown on top of each panel. On the left panel, the most abundant microorganisms are shown in red colour and the less abundant in blue and black. On the right panel, the relative abundance increment in fold change is coloured by red, while the decrease in fold change is coloured in green. The black colour indicates if there was no fold change. The asterisks close to the left and to the right panels indicate the significance of the phase and reactor effects, respectively ( $* \mathrm{P} \leq 0.05 ; * * \mathrm{P} \leq 0.01 ; * * * \mathrm{P} \leq 0.001)$, on the variation in average microbial abundance.

Figure 5: General trends of the most abundant microorganisms classified at genus level with respect to changes in operational phases (Phase I, Phase II, Phase III, Phase IV and Phase V). Abundance was calculated from averaged row data as logarithm of the ratio between each phase (II, III, IV and 
V) and the reference phase (Phase I). The obtained results are denoted as Phase II (Phase II versus I), Phase III (Phase III versus I), Phase IV (Phase V versus I) and Phase V (Phase V versus I).

Trends are classified in: a) linear; b) quadratic; c) cubic; d) mixed shapes of variation, according to the general linear models analysis (GLM).

Figure 6: The percentage of relative abundance of dominant microorganisms ( $>0.5$ OTUs ) with a change in the operational phase: Phase I (R1 and R2), Phase II (R1 and R2) and Phase V (R1 and R2). 


\section{Tables}

2 Table 1. Overview of process conditions and sequencing results. Co-digestion at HRTs of 30, 20, 15

3 and 10 days, with corresponding co-substrate compositions in R1 and R2. Feedstock composition is

4 shown as the ratios of sludge, food waste, grass clippings and garden waste, respectively, for R1

5 and R2 (all VS-based).

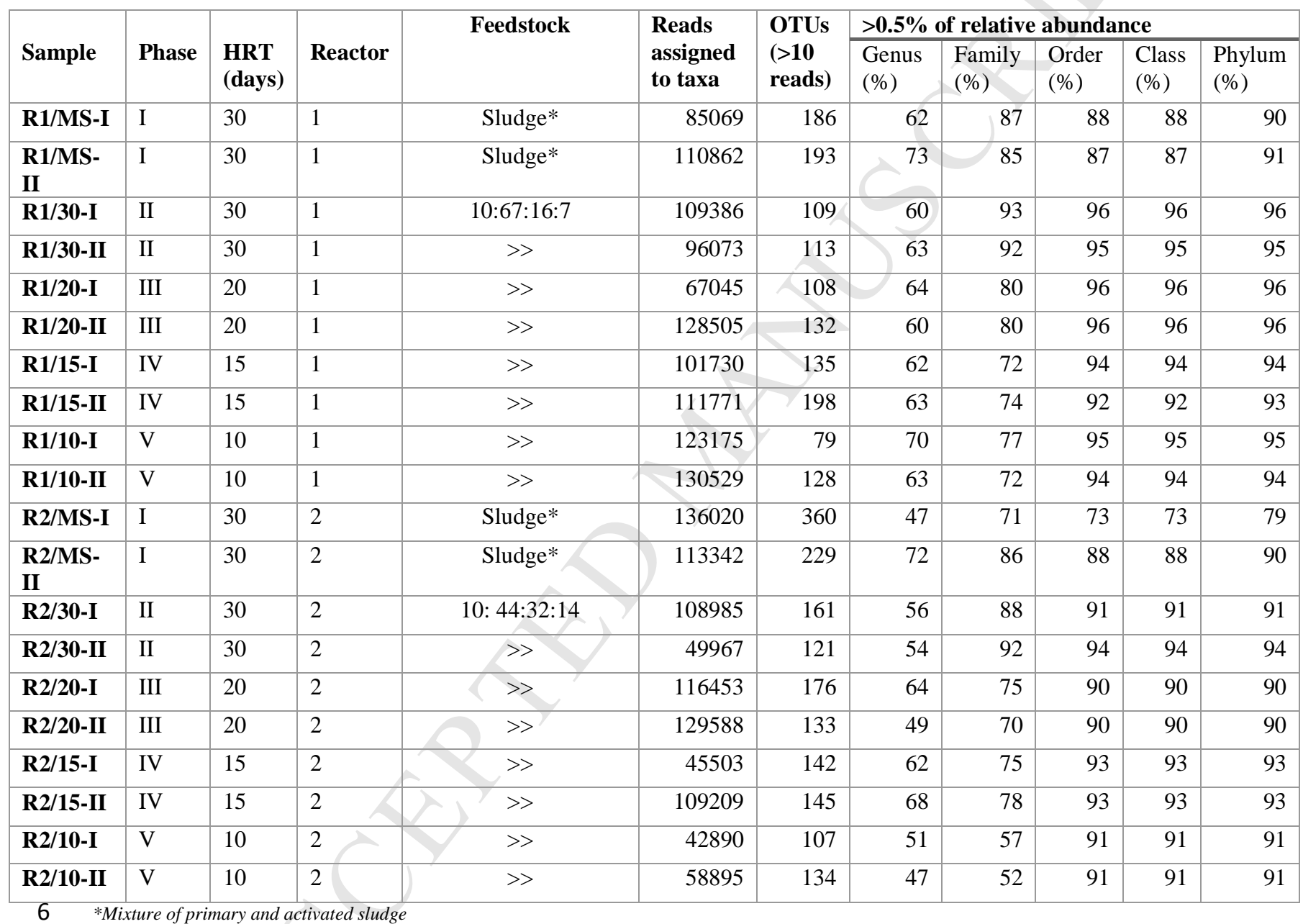

$6 \quad *$ Mixture of primary and activated sludge

7

8

9 
Table 2. Significant sources of variation for AD biochemical performance parameters obtained in single-trait linear model analyses considering phases (Phases I-V) and reactors (R1 and R2) as fixed effects and the microbial abundance as a covariate. The P-value of microbial abundance is reported for each model run, and significant results $(\mathrm{P} \leq 0.05)$ are shown in bold and green font. The direction of the variations was indicated by different colours (blue: same variation; red: opposite variation; white: close to zero variation). When phase and reactor effects resulted as significant $(\mathrm{P} \leq 0.05)$ in a model, they were indicated with a $\mathrm{P}$ or $\mathrm{R}$ superscript close to the $\mathrm{P}$-value of microbial abundance. Only the most interesting OTUs and biochemical parameters were reported (an extended list is provided in Table S-1).

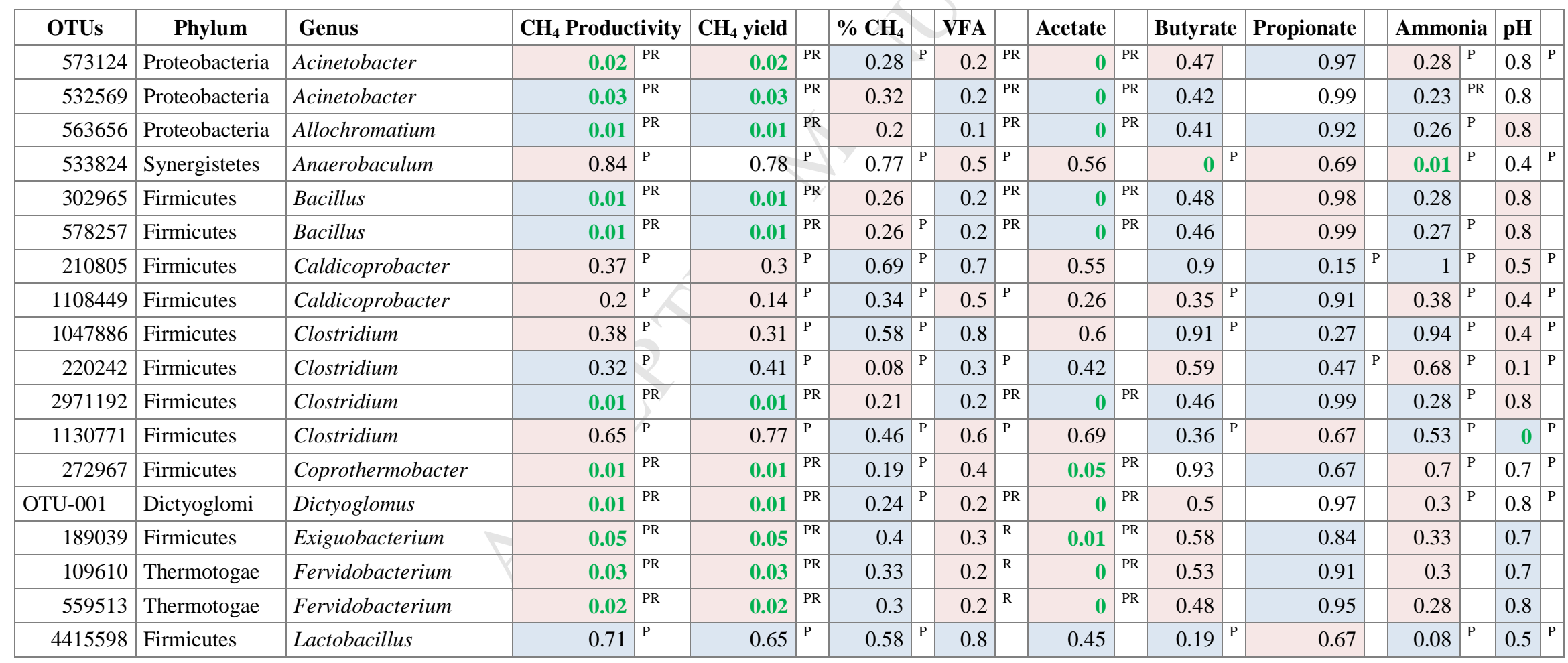




\begin{tabular}{|c|c|c|c|c|c|c|c|c|c|c|c|c|c|c|c|c|c|c|c|c|}
\hline 3851582 & Firmicutes & Lactobacillus & 0.98 & $P$ & 0.95 & $\mathrm{P}$ & 0.47 & $\mathrm{P}$ & 0.7 & & 0.64 & & 0.15 & $\mathrm{P}$ & 0.99 & & 0.08 & $\mathrm{P}$ & 0.7 & $P$ \\
\hline 592689 & Euryarchaeota & Methanosarcina & 0.12 & PR & 0.13 & PR & 0.5 & $\mathrm{P}$ & 0.1 & $\mathrm{P}$ & 0.02 & PR & 0.26 & $\mathrm{P}$ & 0.84 & & 0.11 & $\mathrm{P}$ & 0.8 & $\mathrm{P}$ \\
\hline 369183 & Euryarchaeota & Methanothermobacter & 0.77 & PR & 0.8 & $P$ & 0.65 & $\mathrm{P}$ & 0.8 & & 0.52 & $R$ & 0.73 & & 0.75 & & 0.45 & $\mathrm{P}$ & 0.7 & $\mathrm{P}$ \\
\hline 167215 & Firmicutes & Proteiniclasticum & 0.01 & PR & 0.02 & PR & 0.27 & $\mathrm{P}$ & 0.2 & PR & $\mathbf{0}$ & PR & 0.48 & & 0.96 & & 0.28 & $\mathrm{P}$ & 0.8 & \\
\hline OTU-002 & Thermotogae & S1 & 0.76 & PR & 0.82 & $\mathrm{P}$ & 0.18 & $\mathrm{P}$ & 0.3 & $\mathrm{P}$ & 0.85 & $\mathrm{R}$ & 1 & & 0.08 & $\mathrm{P}$ & 0.82 & $\mathrm{P}$ & 0.5 & $\mathrm{P}$ \\
\hline 777316 & Thermotogae & $\mathrm{S} 1$ & 0.05 & $\mathrm{P}$ & 0.05 & $\mathrm{P}$ & 0.21 & $\mathrm{P}$ & 0.6 & & 0.13 & & 0.79 & & 0.57 & & 0.97 & $\mathrm{P}$ & 0.6 & $\mathrm{P}$ \\
\hline 555945 & Firmicutes & SMB53 & 0.01 & PR & 0.01 & PR & 0.22 & $\mathrm{P}$ & 0.1 & PR & 0 & PR & 0.44 & & 0.96 & & 0.27 & $\mathrm{P}$ & 0.8 & \\
\hline 821325 & Firmicutes & Solibacillus & 0.01 & PR & 0.02 & PR & 0.27 & & 0.2 & PR & $\mathbf{0}$ & PR & 0.47 & & 0.97 & & 0.27 & $P$ & 0.8 & \\
\hline 287657 & Firmicutes & Solibacillus & 0.02 & PR & 0.02 & PR & 0.31 & & 0.2 & PR & $\mathbf{0}$ & PR & 0.4 & & 0.98 & & 0.22 & $\mathrm{R}$ & 0.8 & \\
\hline 1110842 & Firmicutes & Syntrophomonas & 0.57 & PR & 0.65 & $P$ & 0.27 & $P$ & 0 & PR & 0.47 & $\mathrm{R}$ & 0.59 & $\mathrm{P}$ & 0.03 & $P$ & 0.63 & P & 0.3 & $\mathrm{P}$ \\
\hline 2677385 & Firmicutes & Syntrophomonas & 0.02 & PR & 0.02 & PR & 0.3 & & 0.2 & $\mathrm{R}$ & $\mathbf{0}$ & PR & 0.45 & & 0.95 & & 0.26 & $P$ & 0.8 & \\
\hline 203894 & Firmicutes & Syntrophomonas & 0.89 & $P$ & 0.85 & $\mathrm{P}$ & 0.77 & $\mathrm{P}$ & 0.4 & $P$ & 0.6 & & 0.01 & $\mathrm{P}$ & 0.57 & & 0.02 & $\mathrm{P}$ & 0.5 & $\mathrm{P}$ \\
\hline 247170 & Firmicutes & Thermacetogenium & 0.34 & $\mathrm{P}$ & 0.27 & $P$ & 0.8 & $\mathrm{P}$ & 0.8 & & 0.46 & & 0.97 & $\mathrm{P}$ & 0.12 & & 0.82 & $\mathrm{P}$ & 0.5 & $\mathrm{P}$ \\
\hline 248523 & Firmicutes & Thermacetogenium & 0.35 & $\mathrm{P}$ & 0.27 & $\mathrm{P}$ & 0.87 & $\mathrm{P}$ & 0.9 & & 0.43 & & 0.75 & $\mathrm{P}$ & 0.15 & $\mathrm{P}$ & 0.62 & P & 0.3 & $\mathrm{P}$ \\
\hline 242302 & Firmicutes & Thermacetogenium & 0.23 & $\mathrm{P}$ & 0.17 & $\mathrm{P}$ & 0.38 & $\mathrm{P}$ & 0.8 & & 0.36 & & 0.64 & $\mathrm{P}$ & 0.61 & & 0.66 & $\mathrm{P}$ & 0.4 & $\mathrm{P}$ \\
\hline 566078 & Bacteroidetes & Thermonema & $\mathbf{0}$ & $\mathrm{P}$ & 0 & $\mathrm{P}$ & 0.11 & $\mathrm{P}$ & 0.1 & P & 0 & $\mathrm{P}$ & 0.49 & & 0.84 & & 0.36 & $P$ & 0.8 & $\mathrm{P}$ \\
\hline
\end{tabular}




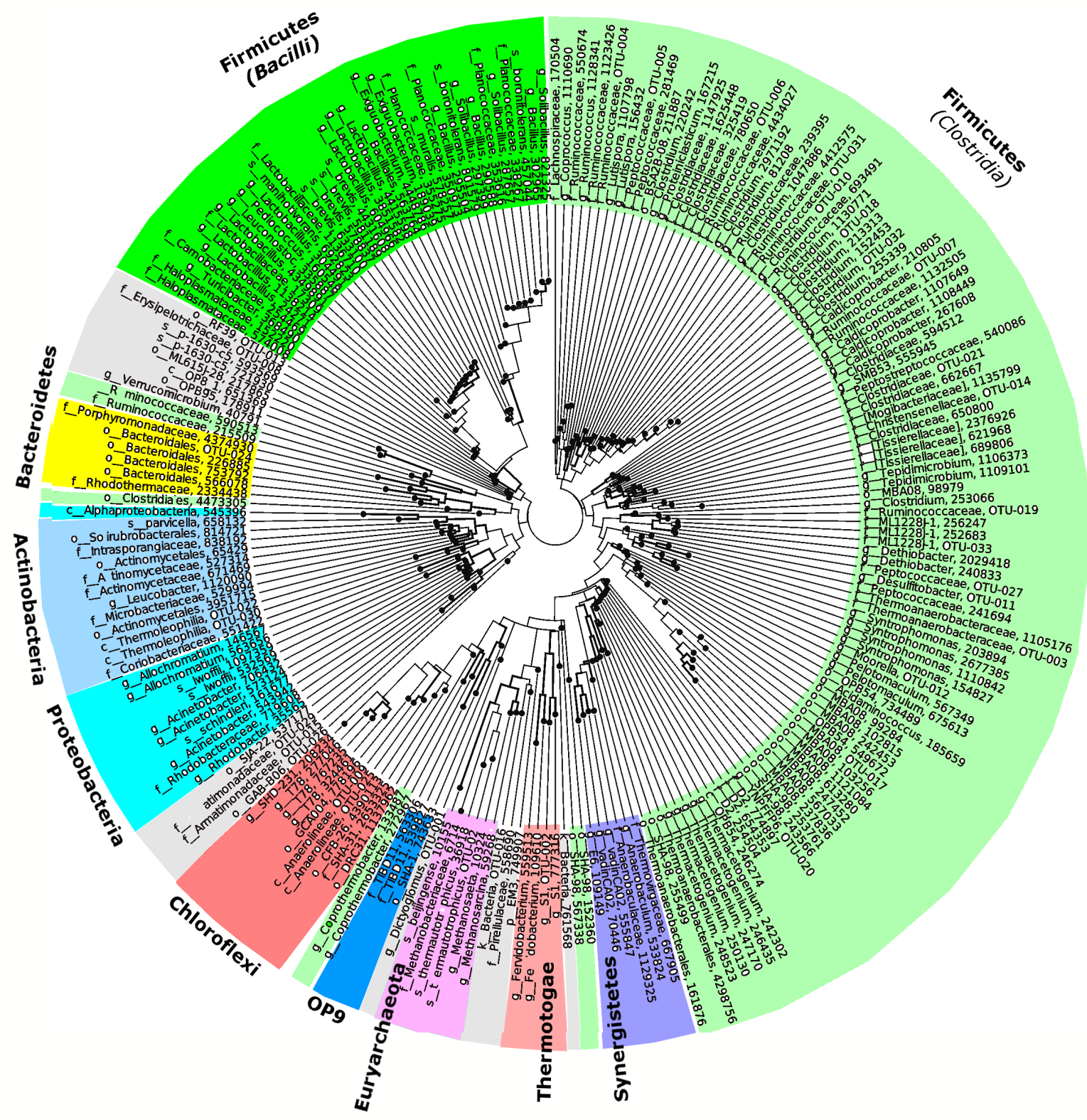

Figure 1 


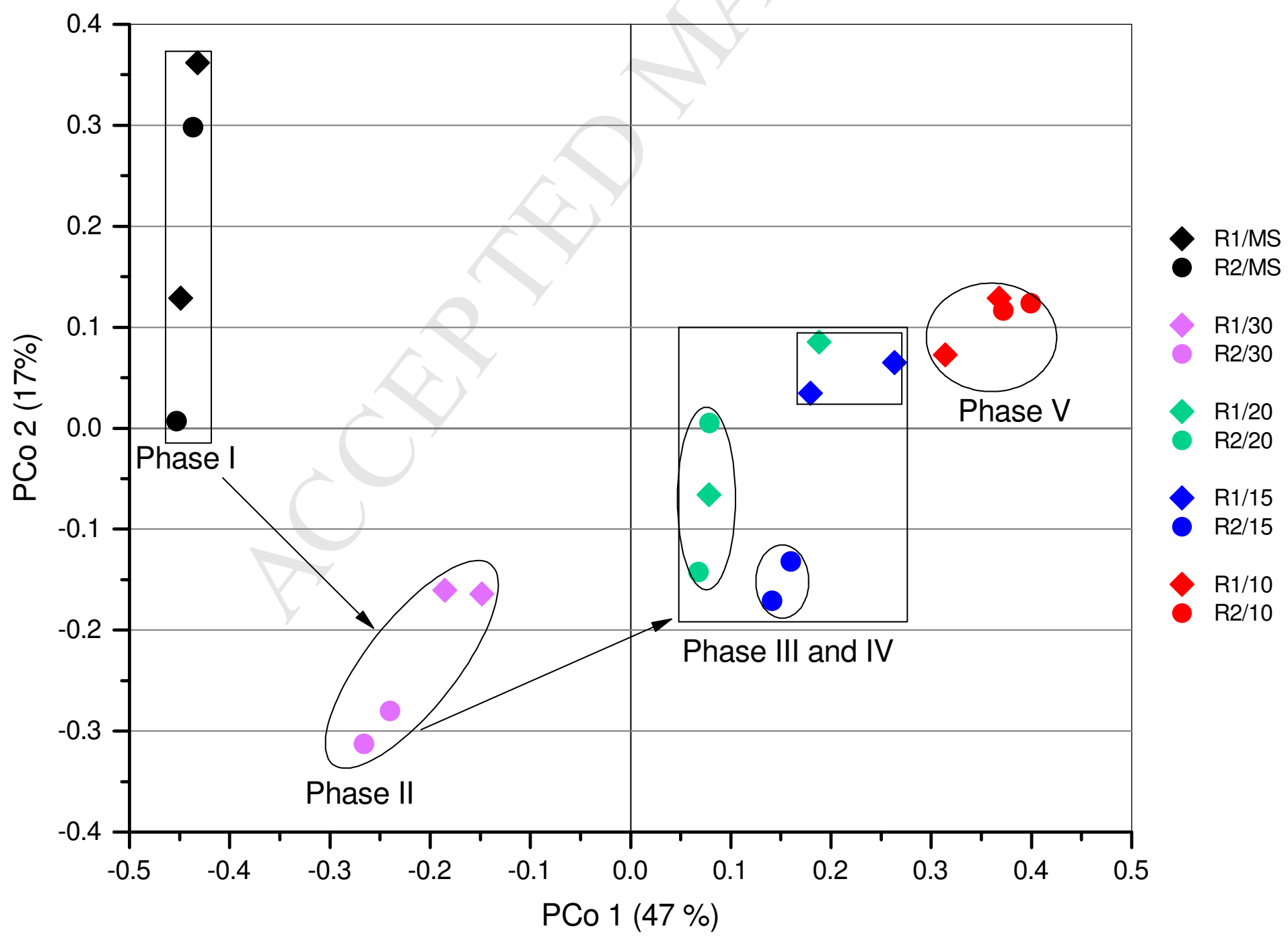



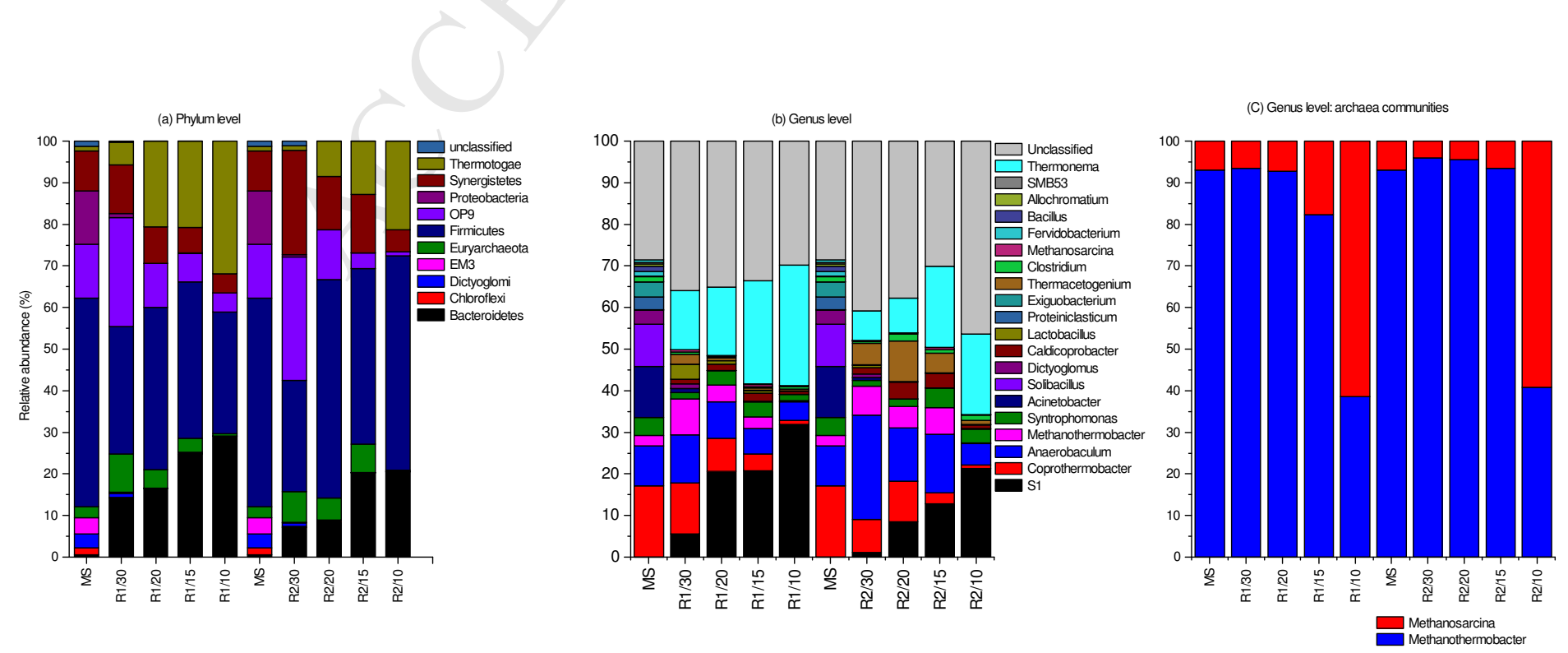

Figure 3 
Click here to download high resolution image
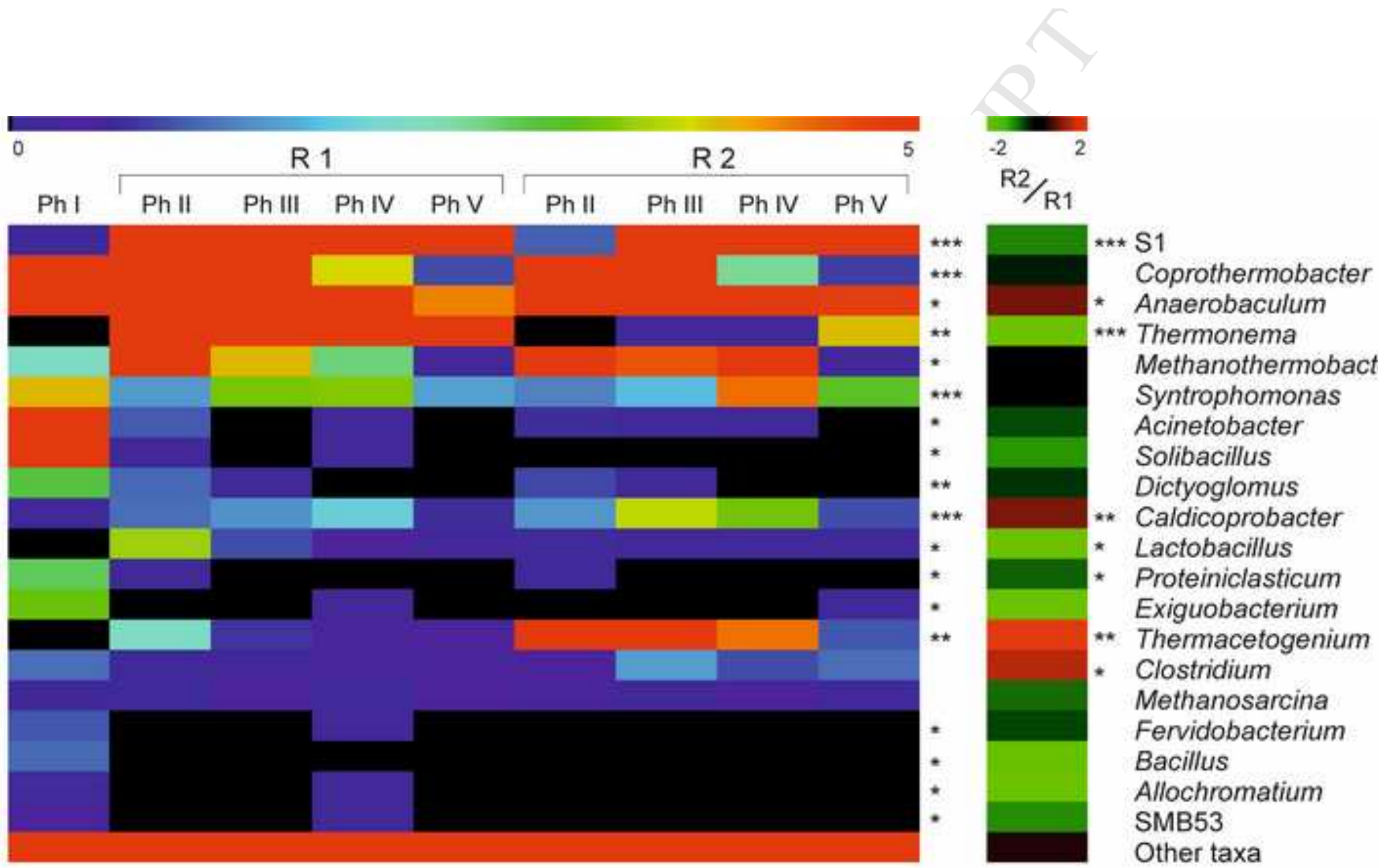

* Anaerobaculum

*** Thermonema

Methanothermobacter

Syntrophomonas

Acinetobacter

Solibacillus

Dictyoglomus

** Caldicoprobacter

* Lactobacillus

* Proteiniclasticum Exiguobacterium

** Thermacetogenium

* Clostridium

Methanosarcina

Fervidobacterium

Bacillus

Allochromatium

SMB53

Other taxa 

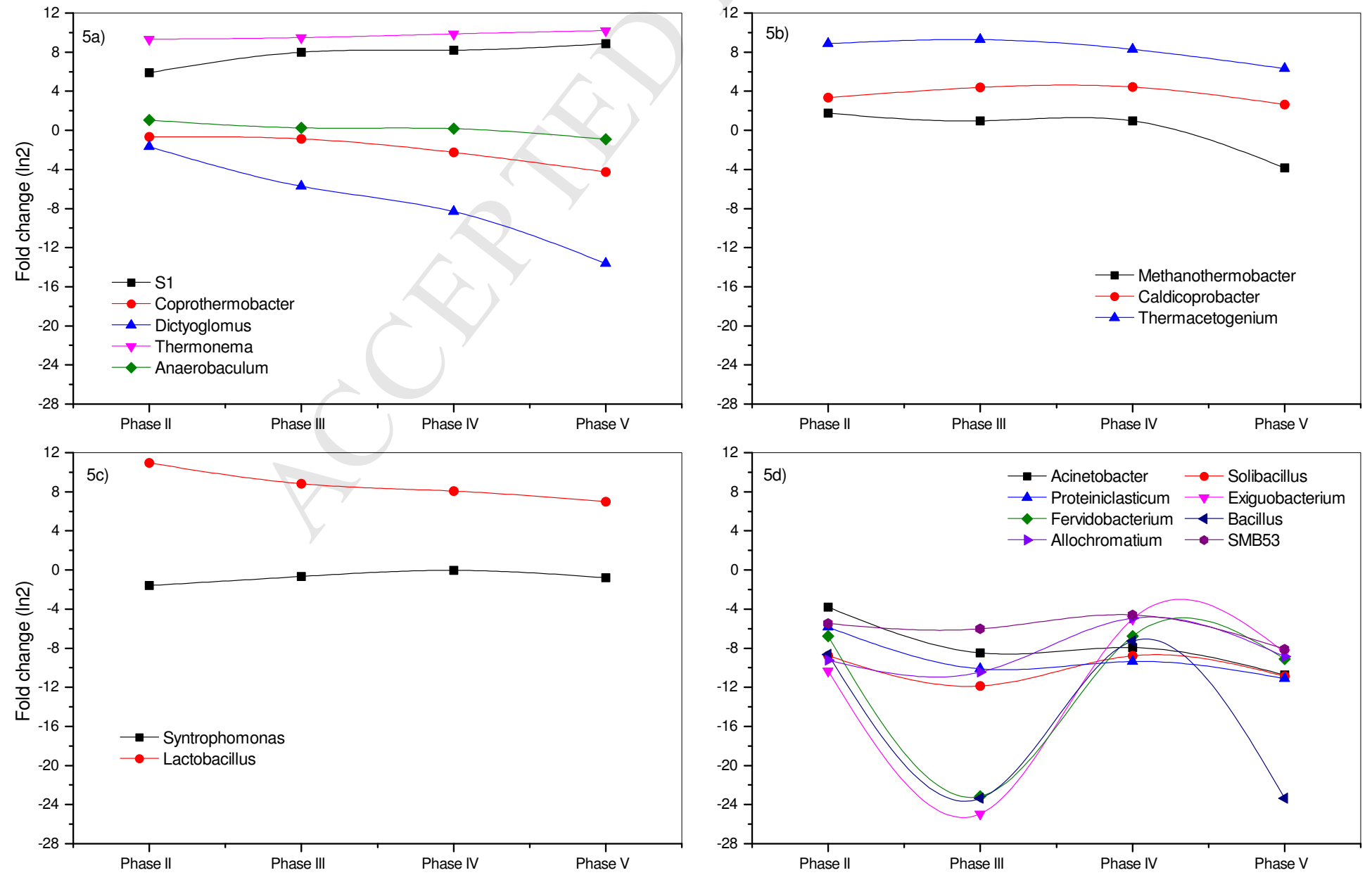

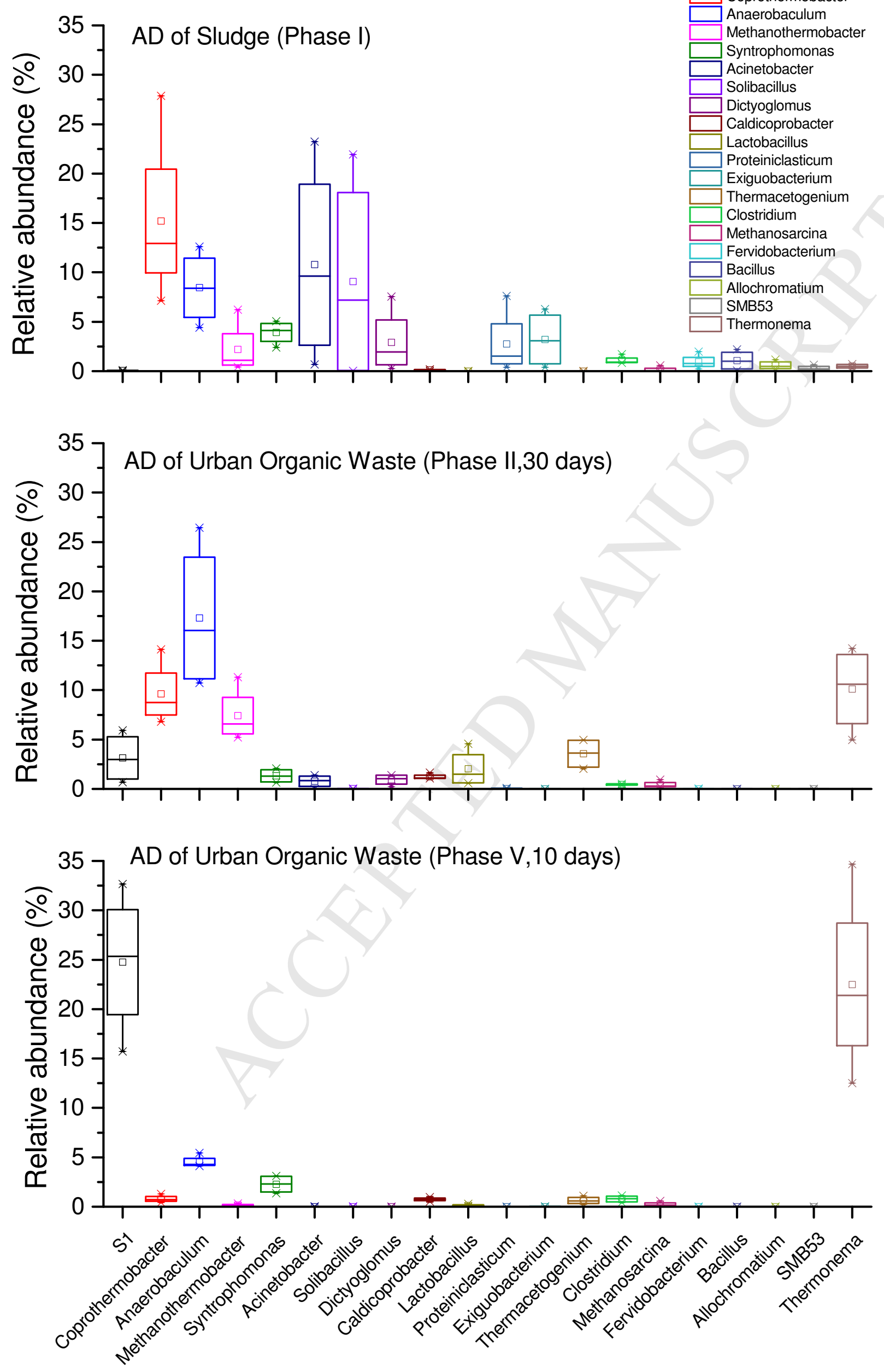
DTU Environment

To

Water Research

16 March 2017

Highlights: Concerning manuscript for publication in Water Research

Thermonema was dominant in co-digestion of sewage sludge and urban organic waste.

Potential pathogenic Acinetobacter found in sludge disappeared during codigestion.

When reducing hydraulic retention time, Methanothermobacter decreased in abundance.

Methane and acetate significantly correlated to Acinetobacter and Bacillus abundance.

$>$ Ammonia production significantly increased with the presence of Syntrophomonas.

Best regards,

Temesgen Fitamo (PhD student) and Co-authors

DTU Environment

Technical University of Denmark Department of

Environmental Engineering
Tel +4545251600

Dir. +4545251585

Fax +45 45932850 tefi@env.dtu.dk www.env.dtu.dk 